\title{
A Meta-Analysis on Higher-Risk Sexual Behavior of Women in 28 Third World Countries
}

\author{
Asres Berhan, Yifru Berhan* \\ Hawassa University College of Medicine and Health Sciences, Hawassa, Ethiopia. \\ Email: *yifrub@yahoo.com
}

Received April 13 ${ }^{\text {th }}, 2012$; revised May $8^{\text {th }}, 2012$; accepted May $18^{\text {th }}, 2012$

\begin{abstract}
Background: Previous reports on sexual behaviours and risks of HIV infection in relation to socioeconomic status of women were contradictory. The purpose of this study was to determine the consistency of risky sexual behaviour among women with regard to their age, residence, educational level and wealth index. Methods: Subgroup and pooled meta-analysis was done on risky sexual behaviour and HIV prevalence of women aged 15 - 49 years using the recent Demographic and Health Surveys data (DHS 2003-2009) from 28 countries in and outside Africa. Pooled and individual countries odds ratios were calculated using Mantel-Haenszel $(\mathrm{M}-\mathrm{H})$ statistical method. Random effect analytic model was applied since there was significant heterogeneity among surveys $\left(\mathrm{I}^{2}>50 \%\right)$. Sensitivity analysis was also done to examine the effect of outliers. Results: Out of 207,776 women reported to have sex within 12 months prior to the respective surveys, 36,530 (17.6\%) were practicing higher-risk sex. Risky sexual behavior was found to have statistically significant association with women living in urban areas, attained secondary and above education and owned middle to highest wealth index. Sensitivity analysis demonstrated the stability of the pooled odds ratios for outliers. Better education attainment, high wealth index and being employed were also associated with high HIV prevalence. Conclusion: This analysis has shown the high prevalence of higher-risk sexual behaviour and high HIV infection among wealthier and better educated women regardless of geographic location of the selected low to middle income countries. Further study is required to establish how and why being good in socioeconomic status associated with risky sexual behaviour.
\end{abstract}

Keywords: Education; Employment; Higher-Risk Sex; HIV-Prevalence; Meta-Analysis; Residence; Wealth

\section{Introduction}

The proportion of women and girls accounts for more than half of the global estimate of people living with HIV [1]. In Sub-Saharan Africa (SSA), more women than men are infected with HIV, and the biggest driver of HIV transmission is heterosexual sex [1,2]. Several literatures gave emphasis on high association of HIV sero-prevalence with high socioeconomic status in SSA [3-5]; however, to the best of our knowledge, there was no systematic review or meta-analysis that assesses the association of higher-risk sex with regard to socioeconomic status in either SSA or other low and middle income countries using DHS data.

The spread of HIV, for the most part, is a function of higher risk sex [1]. It was reported that nearly three fourths of HIV-infected women acquired the virus through higher-risk sex [6]. Besides women's physiologic vulnerability via heterosexual sex, several investi-

\footnotetext{
*Corresponding author.
}

gators attributed unemployment and lack of education as exposing factors for women's susceptibility to HIV infection [7-9]. Some other studies also ascribed poverty as predisposing factor for HIV infection $[3,10,11]$. At the global level, there is a positive correlation between countries' HIV prevalence and poverty, as measured by per capita income, income inequality, or absolute poverty [12]. Likewise, it has been said that women are more vulnerable to HIV infection mainly because of less secure employment and lower incomes [13]. However, such conclusions were made based on the overall population of the low income countries without disaggregating the population by socioeconomic status.

Previous reports were not consistent on association of risky sexual behaviour/HIV infection with level of education and wealth/economic status. According to a study, secondary or higher education was protective against HIV infection [14]. Other authors reported that less educated women are becoming more vulnerable to HIV than highly educated women [2]. To the contrary, analysis 
done using the 2003 DHS of Kenya \& Ghana concluded that HIV epidemic was no longer driven by poverty; rather, it was wealth and a number of other socio-demographic factors that explain sexual risk-taking behaviour that puts people at risk [15]. Similarly, another analysis including eight countries DHS from SSA countries demonstrated that adults with highest wealth index have a higher prevalence of HIV than those with lowest wealth index [4]. A systematic review conducted in 2002 deduced that, in Africa, higher educational attainment was often associated with a greater risk of HIV infection [5]. Still another study done in Uganda also claimed that level of education and urban residence was significantly associated with HIV infection [16].

Considering those conflicting results on the association of higher-risk sexual behavior and HIV infection with educational and economic status, we were inspired to do a meta-analysis using the recently released DHS data by including as many countries DHS as possible from different corner of the third world. The objective was to determine the consistency of risky sexual behaviour among women with regard to their age, residence, educational level and wealth index.

\section{Methods}

\subsection{How DHS Data Collected}

Household-based data have been collected for over 20 years in different parts of the less developed world. The detail methodology how DHS data collected is found elsewhere [17]. In brief, DHS data are characterized by cross sectional study design, large sample sizes and being national representative. Almost all the surveys applied a two-stage cluster sampling method. Since DHS were intended to address household based health issues, strata for urban and rural households were used to select study respondents. Each DHS followed a standard procedure of data collection and data presentation. Additionally, majority of the surveys used same definitions of terms and similar questionnaires developed by MEASURE DHS [18]. Higher-risk sex and HIV prevalence are some of the HIV related focus areas of all DHS with the same methods of data collection and same data presentation across all countries. DHS data related to sexual behavior and HIV infection were gathered by interviewing individuals who were sampled as study subject and gave consent for both interview and blood draw for HIV test.

\subsection{Study Selection \& Inclusion Criteria}

The data sources used for this meta-analysis were DHS done between year 2003 and 2009. It was possible to download 51 DHS from electronic databases published in MEASURE DHS website up to late July 2011 [17]. How- ever, only 28 countries DHS from different parts of the world were eligible for this meta-analysis: 23 from Africa (Benin, Burkina Faso, Cameroon, Chad, Cote d'Ivoire, Ethiopia, Ghana, Guinee, Kenya, Lesotho, Liberia, Malawi, Mali, Namibia, Nigeria, Rwanda, Sierra Leone, South Africa, Swaziland, Tanzania, Uganda, Zambia and Zimbabwe) and 5 from outside Africa (Bolivia, Guyana, Haiti, Honduras and Philippines). The criteria for the DHS to be included in this analysis were the availability of data on women's higher-risk sex and consistency in higher-risk sex data grouping in relation to socioeconomic characteristics. The South African 2003 DHS didn't include the data for higher-risk sex in relation to wealth index; accordingly, the analysis of risky sex by wealth index was done for 27 countries.

\subsection{Operational Definition}

All DHS defined higher-risk sexual intercourse as to mean having sex with a man who was neither a spouse nor a cohabiting partner in the past 12 months prior to the survey. Although majority of DHS described the household's wealth assets as wealth quintiles, wealth index and wealth quintiles were found used interchangeably. In all DHS, wealth index was used to describe household assets including the source of water, type of toilet facility, materials used for housing construction, ownership of various durable goods, ownership of agricultural land, ownership of domestic animals and ownership and use of mosquito nets. Wealth index is used consistently in all sections of this article.

All DHS classified wealth index as lowest, second, middle, fourth and highest. On the other hand, majority of DHS grouped educational levels as no education, primary, secondary and above. In this meta-analysis, before the statistical analysis, all the data were changed to binary data in the form of primary or no education vs secondary and above, low or lowest vs middle to highest wealth index, and employed vs unemployed. Otherwise, women's residence and employment status were found being dichotomized in each DHS data.

\subsection{Statistical Analysis}

All statistical analyses were done using Review Manager Software (RevMan 5) [19]. Since the test for heterogeneity among different countries' DHS data uncovers inconsistency $\left(\mathrm{I}^{2}>50 \%\right)$ in all of the meta-analyses, we used the random effect model. The advantage of random effects analytic model over a fixed model is that it accounts for inter-surveys variation and provides a more conservative effect. Sensitivity analyses were also done to examine the effect of outliers by comparing the pooled odds ratios before and after elimination of one country at a time. Mantel-Haenszel (M-H) statistical method was ap- 
plied to determine individual country's odds ratios and pooled odds ratios. Odds ratios were calculated for potential associations of higher-risk sexual behavior with residence, level of education and wealth index. Odds ratios were also calculated for association of HIV prevalence with level of education, employment and wealth index. Each Forest Plot shows the year DHS done, total women who reported to have sexual intercourse in 12 months and proportion of higher-risk, odds ratios and 95\% CI. To complement the higher-risk sexual behaviour data, meta-analysis was also done on HIV prevalence in relation to women's level of education, wealth index, and employment status.

\section{Results}

Out of 207,776 women aged 15 - 49 years and who had sexual intercourse within 12 months prior to the respective surveys, 36,530 (17.6\%) reported to have higher-risk sex. As shown in Figure 1, in all included countries but

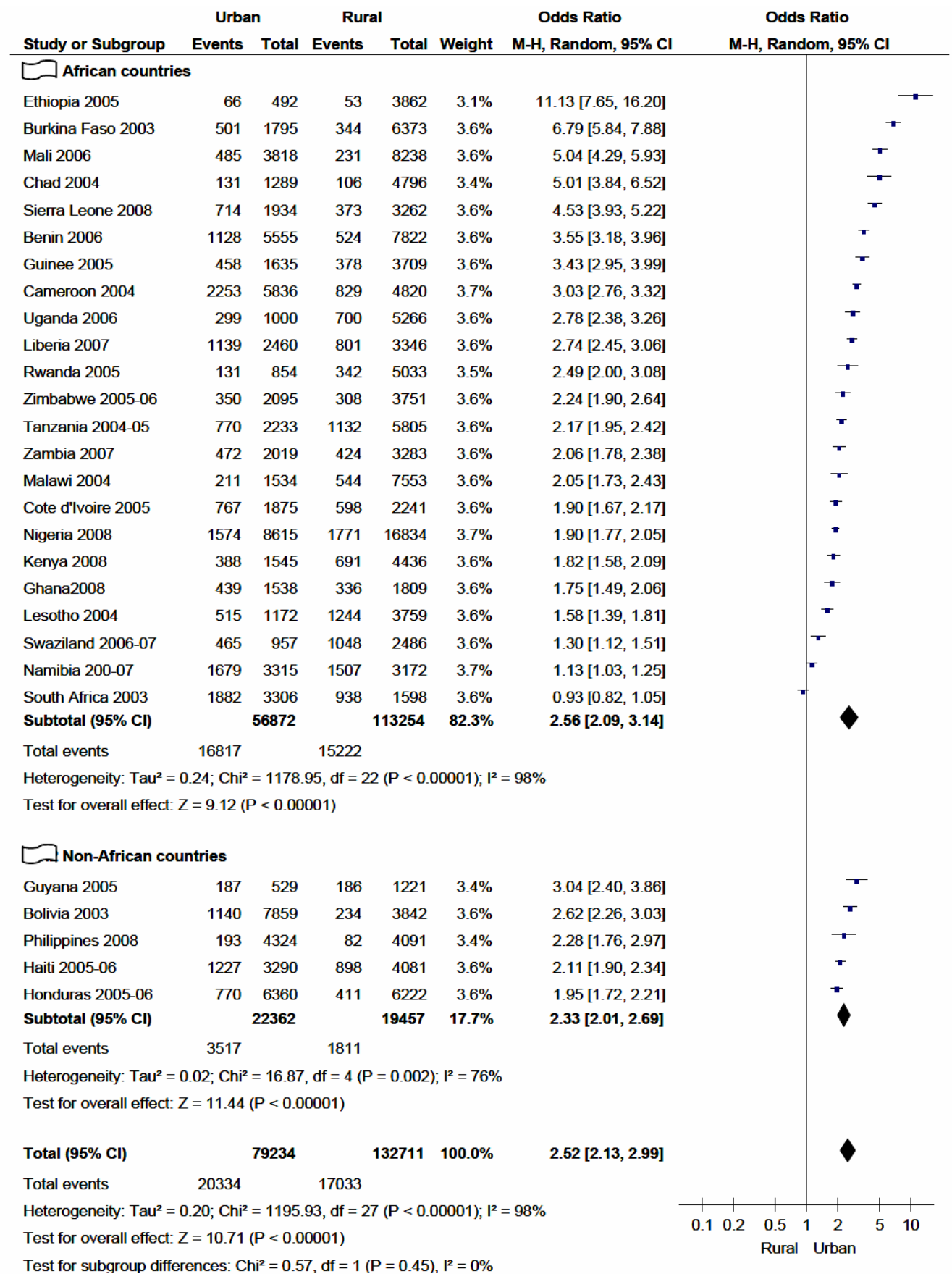

Figure 1. Practice of higher-risk sex in 12 months among women age 15 - 49 years in relation to their residence (2003-2009). 
South Africa, the number of women who had higher-risk sexual intercourse was higher among urban inhabitants. As a result, the overall proportion of higher-risk sex among women who live in urban was found to be almost two-fold (25.5\%) of those women who live in rural areas, $25.7 \%(20,331 / 79,234)$ and $12.8 \%$ (17,033/132,711), respectively.

The meta-analysis also demonstrated that higher-risk sex was strongly associated with women who live in urban areas in both African and non-African countries included in this analysis. The highest odds ratio was spoted in Ethiopia (OR = 11.1; 95\% CI, 7.65 - 16.20) and followed by Burkina Faso $(\mathrm{OR}=6.8$, 95\% CI 5.84 -
7.88). The pooled/overall odds ratio with the random effect model was found to be 2.5 (95\% CI, 2.13 - 2.99), which is almost equivalent to the subtotal odds ratio of African countries (2.56) but higher than subtotal odds ratio of non-African countries (2.33). However, the sensitivity analysis of risky sex with respect to their residence indicated that no individual country significantly affected the over all odds ratio-the over all odds ratio swings between 2.4 and 2.6 when any of the included country is excluded. As a result, the test for subgroup differences (African vs Non-African countries) didn't demonstrate statistical significance $(\mathrm{P}=0.45)$.

As presented in Figure 2, higher risk sex was much

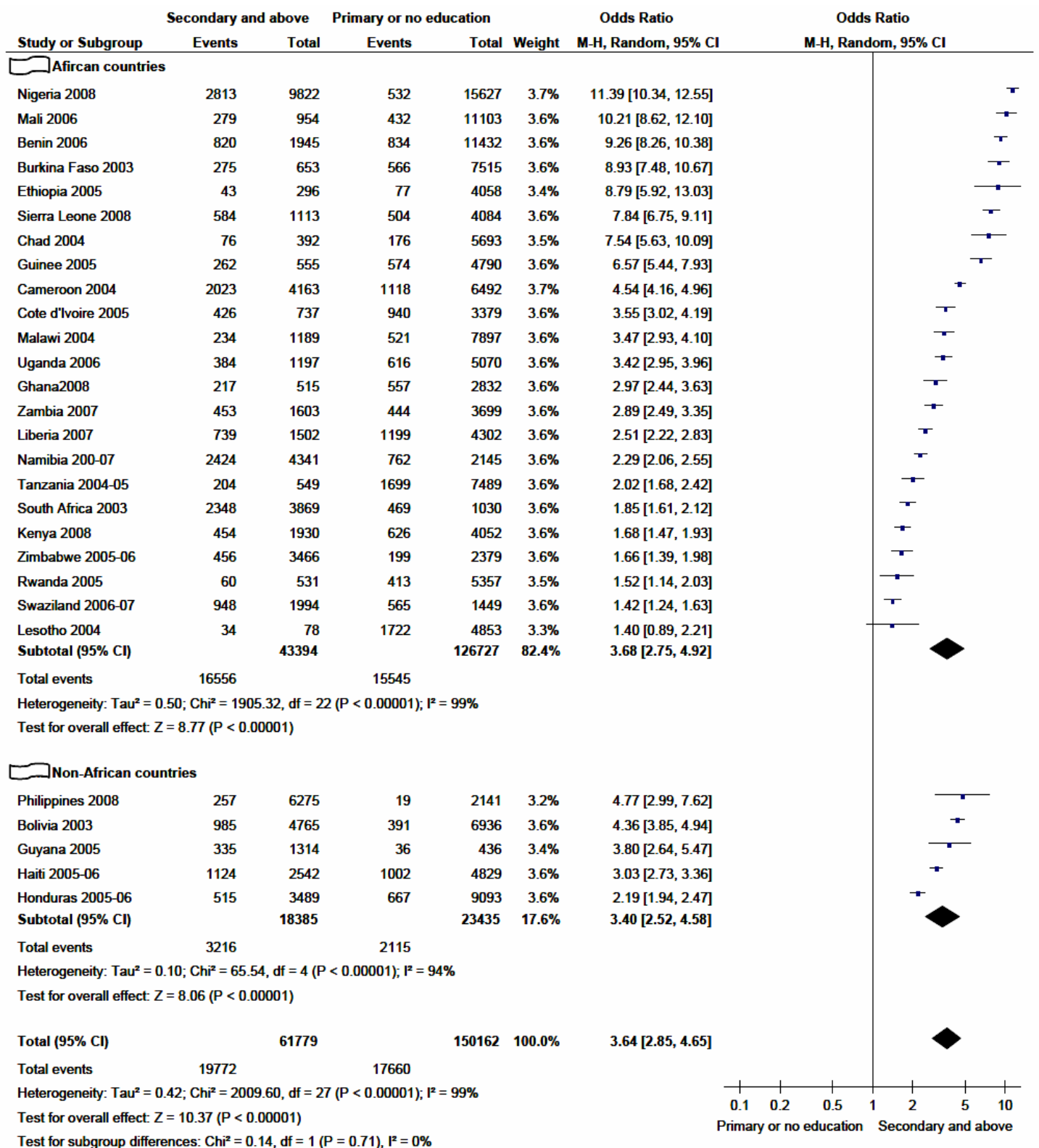

Figure 2. Practice of higher-risk sex in 12 months among women age 15 - 49 years in relation to their educational level (2003-2009). 
more common among women educated to secondary and above, with the highest odds ratio in Nigeria and Mali. In all countries except Lesotho, the association of higherrisk sex with women whose educational level secondary and above was statistically significant in both African and non-African countries. As a result, the pooled odds ratio showed highly statistically significant association of higher-risk sex with better educated women (OR = 3.6; $95 \%$ CI, 2.85 - 4.65), which is very close to subtotal odds ratio of African countries.

Furthermore, sensitivity analysis established that the overall odds ratio was not attributed to the influence of any of included country country. When any of the included country is excluded from the analysis, the pooled odds ratio fall in the range of 3.5 - 3.8. There was no statistical significance in the test for subgroup differences $(\mathrm{P}=0.71)$.

The total percentage of women practicing risky sex in 12 months period was $20.3 \%(26,495 / 130,492)$ and $10.5 \%$ $(8065 / 76,548)$ whose wealth index was clustered as middle to highest and low or lowest, respectively (Figure 3). In the majority of the selected countries, higher-risk

\begin{tabular}{|c|c|c|c|c|c|c|c|c|c|c|}
\hline \multirow[b]{2}{*}{ Study or Subgroup } & \multicolumn{2}{|c|}{ Middle to highest } & \multicolumn{2}{|c|}{ Low or lowest } & \multirow[b]{2}{*}{ Weight } & \multirow{2}{*}{$\begin{array}{c}\text { Odds Ratio } \\
\text { M-H, Random, } 95 \% \mathrm{Cl}\end{array}$} & \multirow{2}{*}{\multicolumn{4}{|c|}{$\begin{array}{c}\text { Odds Ratio } \\
\text { M-H, Random, } 95 \% \mathrm{Cl}\end{array}$}} \\
\hline & Events & Total & Events & Total & & & & & & \\
\hline \multicolumn{11}{|c|}{$\sqsubset$ African countries } \\
\hline Cameroon 2004 & 2607 & 6895 & 490 & 3763 & $3.8 \%$ & $4.06[3.65,4.52]$ & & & & + \\
\hline Nigeria 2008 & 2771 & 15102 & 574 & 10346 & $3.8 \%$ & $3.83[3.48,4.20]$ & & & & $\bar{\tau}$ \\
\hline Chad 2004 & 193 & 3559 & 40 & 2526 & $3.4 \%$ & $3.56[2.53,5.03]$ & & & & $\checkmark$ \\
\hline Sierra Leone 2008 & 901 & 3321 & 187 & 1876 & $3.7 \%$ & $3.36[2.84,3.98]$ & & & & $\rightarrow$ \\
\hline Mali 2006 & 595 & 7361 & 122 & 4696 & $3.7 \%$ & $3.30[2.70,4.02]$ & & & & 5 \\
\hline Burkina Faso 2003 & 712 & 5286 & 131 & 2883 & $3.7 \%$ & $3.27[2.70,3.96]$ & & & & $\rightarrow$ \\
\hline Benin 2006 & 1377 & 8687 & 276 & 4691 & $3.8 \%$ & $3.01[2.63,3.45]$ & & & & - \\
\hline Guinee 2005 & 666 & 3231 & 169 & 2113 & $3.7 \%$ & $2.99[2.50,3.57]$ & & & & 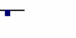 \\
\hline Liberia 2007 & 1506 & 3734 & 433 & 2071 & $3.8 \%$ & $2.56[2.26,2.90]$ & & & & \\
\hline Ethiopia 2005 & 91 & 2530 & 28 & 1824 & $3.2 \%$ & $2.39[1.56,3.67]$ & & & & \\
\hline Uganda 2006 & 764 & 3865 & 234 & 2401 & $3.8 \%$ & $2.28[1.95,2.67]$ & & & & \\
\hline Zimbabwe 2005-06 & 497 & 3653 & 158 & 2192 & $3.7 \%$ & $2.03[1.68,2.45]$ & & & & \\
\hline Ghana2008 & 581 & 2183 & 194 & 1166 & $3.7 \%$ & $1.82[1.52,2.18]$ & & & & \\
\hline Zambia 2007 & 650 & 3284 & 246 & 2017 & $3.7 \%$ & $1.78[1.52,2.08]$ & & & - & \\
\hline Cote d'Ivoire 2005 & 984 & 2616 & 382 & 1499 & $3.8 \%$ & $1.76[1.53,2.03]$ & & & 7 & \\
\hline Tanzania 2004-05 & 1314 & 5035 & 589 & 3003 & $3.8 \%$ & $1.45[1.30,1.62]$ & & & + & \\
\hline Kenya 2008 & 782 & 3956 & 298 & 2025 & $3.8 \%$ & $1.43[1.23,1.65]$ & & & $T$ & \\
\hline Swaziland 2006-07 & 1044 & 2287 & 470 & 1156 & $3.8 \%$ & $1.23[1.06,1.41]$ & & & - & \\
\hline Malawi 2004 & 496 & 5681 & 259 & 3405 & $3.8 \%$ & $1.16[0.99,1.36]$ & & & - & \\
\hline Namibia 200-07 & 2242 & 4481 & 944 & 2006 & $3.8 \%$ & $1.13[1.01,1.25]$ & & & - & \\
\hline Rwanda 2005 & 289 & 3494 & 186 & 2393 & $3.7 \%$ & $1.07[0.88,1.30]$ & & & - & \\
\hline Lesotho 2004 & 1194 & 3342 & 563 & 1590 & $3.8 \%$ & $1.01[0.90,1.15]$ & & & + & \\
\hline Subtotal $(95 \% \mathrm{Cl})$ & & 103583 & & 61642 & $81.7 \%$ & $2.08[1.68,2.56]$ & & & & \\
\hline Total events & 22256 & & 6973 & & & & & & & \\
\hline \multicolumn{11}{|c|}{ Heterogeneity: $\mathrm{Tau}^{2}=0.24 ; \mathrm{Chi}^{2}=945.66, \mathrm{df}=21(\mathrm{P}<0.00001) ; \mathrm{I}^{2}=98 \%$} \\
\hline \multicolumn{11}{|c|}{ Test for overall effect: $Z=6.81(P<0.00001)$} \\
\hline \multicolumn{11}{|c|}{$\square$ Non-African countries } \\
\hline Philippines 2008 & 239 & 5091 & 38 & 3323 & $3.4 \%$ & $4.26[3.02,6.01]$ & & & & \\
\hline Bolivia 2003 & 1139 & 7685 & 237 & 4015 & $3.8 \%$ & $2.77[2.40,3.21]$ & & & & \\
\hline Haiti 2005-06 & 1686 & 4933 & 439 & 2437 & $3.8 \%$ & $2.36[2.10,2.66]$ & & & & \\
\hline Honduras 2005-06 & 918 & 8107 & 262 & 4474 & $3.8 \%$ & $2.05[1.78,2.37]$ & & & & \\
\hline Guyana 2005 & 257 & 1093 & 116 & 657 & $3.6 \%$ & $1.43[1.12,1.83]$ & & & & \\
\hline Subtotal $(95 \% \mathrm{Cl})$ & & 26909 & & 14906 & $18.3 \%$ & $2.37[1.88,2.98]$ & & & & \\
\hline Total events & 4239 & & 1092 & & & & & & & \\
\hline \multicolumn{11}{|c|}{ Heterogeneity: Tau $^{2}=0.06 ; \mathrm{Chi}^{2}=35.61, \mathrm{df}=4(\mathrm{P}<0.00001) ; \mathrm{l}^{2}=89 \%$} \\
\hline \multicolumn{11}{|c|}{ Test for overall effect: $Z=7.31(P<0.00001)$} \\
\hline Total $(95 \% \mathrm{Cl})$ & & 130492 & & 76548 & $100.0 \%$ & $2.13[1.78,2.55]$ & & & & \\
\hline Total events & 26495 & & 8065 & & & & & & & \\
\hline \multicolumn{7}{|c|}{ Heterogeneity: $\mathrm{Tau}^{2}=0.21 ; \mathrm{Chi}^{2}=990.75, \mathrm{df}=26(\mathrm{P}<0.00001) ; \mathrm{I}^{2}=97 \%$} & 1 & 1 & + & + \\
\hline \multicolumn{7}{|c|}{ Test for overall effect: $Z=8.34(P<0.00001)$} & & $\begin{array}{c}0.5 \\
\text { w or lowest }\end{array}$ & ${ }^{1}{ }_{\text {Middle to }}^{2}$ & \\
\hline
\end{tabular}

Figure 3. Practice of higher-risk sex in 12 months among women age 15 - 49 years in relation to their wealth index (20032009). 
sex was significantly associated with women having better wealth index. In Lesotho, Malawi and Rwanda, although there was more proportion of higher-risk sex among relatively wealthy women, there was no statistically significant association.

The subtotal odds ratio of non-African countries is higher than the subtotal odds ratio of African countries. The pooled odds ratio in the sensitivity analysis found to be stable in the absence of any of the included countries. To the maximum, the odds ratio discrepancy was \pm 0.06 with the withdrawal of any of the countrie from the analysis.

The meta-analysis on HIV prevalence in women in relation to their wealth index, employment status and level of education was carried out for 15 countries. Figure 4 shows HIV prevalence among women and its association with the level of their wealth index. The overall proportion of HIV prevalence was reported to be $5.4 \%(3130 / 58,380)$ among women with middle to highest wealth index and 3.7\% (1231/33,203) among women with low or lowest wealth index. The pooled analysis revealed that HIV prevalence was associated with women in the category of middle to highest wealth index $(\mathrm{OR}=1.6$; 95\% CI, 1.21 - 2.17). Although the proportions of HIV prevalence in Benin, Kenya, Mali and Sierra Leone were reported to be higher in women with middle to highest wealth index, the meta-analysis did not show statistically significant association. In general, except Dominican Republic, there was high proportion of HIV prevalence among women with middle to highest wealth index in all countries selected for this analysis. The sensitivity analysis also showed the pooled odds ratio being in the range of 1.5 - 1.8.

As presented in Figure 5, HIV infection was also strongly associated with women who were employed at the time of the survey with an over all odds ratio of 1.4 (95\% CI, 1.21 - 1.59). However, the proportion of HIV prevalence in Dominican Republic, Liberia and Sierra Leon was higher among unemployed women. From the sensitivity analysis, it was found that the overall odds ratio was more or less unchanged with exclusion of any of the included countries.

The overall result for the analysis of HIV prevalence with respect to level of education doesn't demonstrate significant association (Figure not seen). But sensitivity analysis discovered that, if Dominican Republic was excluded from the analysis, the pooled odds ratio of HIV prevalence would be significantly associated with women who attended secondary schools and above.

\section{Discussion}

Although many investigators attributed poverty and lack of education as a contributing factor for higher-risk sex among women [20-22], this meta-analysis demonstrated that women who were educated to secondary or above, living in urban areas and having better wealth were found engaged in risky sexual practice than their counterparts irrespective of the geographic location of the studied countries. Since educated women are more likely to become wealthy and live in urban areas; better education attainment, good wealth and living in urban area are very likely to be inter-linked.

In several literature, it has been described that risky

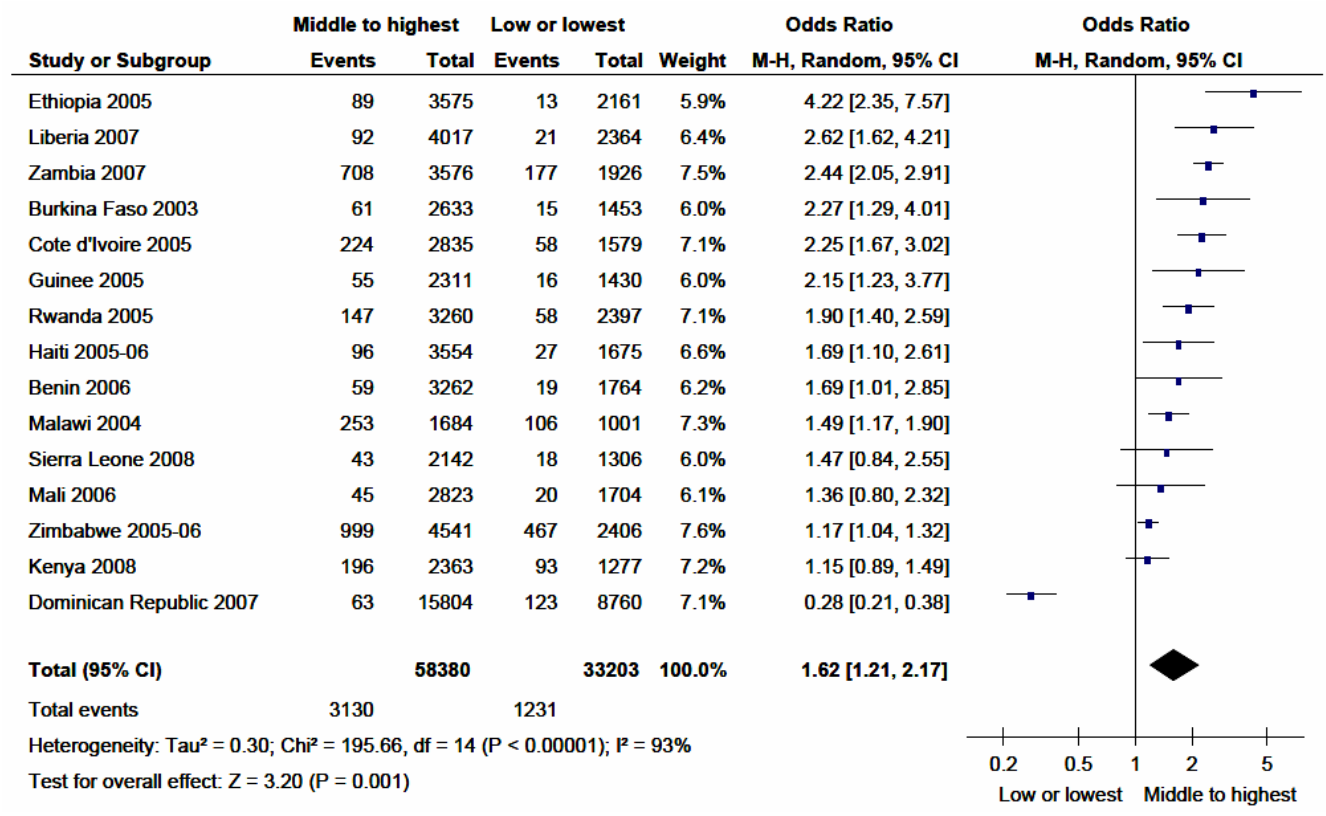

Figure 4. Prevalence of HIV infection among women age 15 - 49 years in relation to their wealth index (2003-2009). 


\begin{tabular}{|c|c|c|c|c|c|c|c|c|}
\hline \multirow[b]{2}{*}{ Study or Subgroup } & \multicolumn{2}{|c|}{ Currently employed } & \multicolumn{2}{|c|}{ Not currently employed } & \multirow[b]{2}{*}{ Weight } & \multirow{2}{*}{$\begin{array}{c}\text { Odds Ratio } \\
\text { M-H, Random, } 95 \% \mathrm{Cl}\end{array}$} & \multirow{2}{*}{\multicolumn{2}{|c|}{$\begin{array}{l}\text { Odds Ratio } \\
\text { M-H, Random, } 95 \% \text { CI }\end{array}$}} \\
\hline & Events & Total & Events & Total & & & & \\
\hline Kenya 2008 & 224 & 2110 & 67 & 1531 & $8.1 \%$ & $2.60[1.96,3.44]$ & & $\longrightarrow$ \\
\hline Haiti 2005-06 & 80 & 2744 & 40 & 2486 & $6.2 \%$ & $1.84[1.25,2.69]$ & & \\
\hline Mali 2006 & 44 & 2726 & 18 & 1800 & $4.0 \%$ & $1.62[0.94,2.82]$ & & \\
\hline Benin 2006 & 64 & 4030 & 10 & 994 & $3.1 \%$ & $1.59[0.81,3.10]$ & & \\
\hline Ethiopia 2005 & 46 & 1981 & 51 & 3423 & $5.9 \%$ & $1.57[1.05,2.35]$ & & \\
\hline Burkina Faso 2003 & 15 & 578 & 60 & 3508 & $3.8 \%$ & $1.53[0.86,2.71]$ & & \\
\hline Guinee 2005 & 59 & 2939 & 11 & 794 & $3.2 \%$ & $1.46[0.76,2.79]$ & & \\
\hline Cote d'Ivoire 2005 & 212 & 2988 & 71 & 1422 & $8.2 \%$ & $1.45[1.10,1.92]$ & & \\
\hline Zimbabwe 2005-06 & 718 & 2994 & 746 & 3949 & $11.5 \%$ & $1.35[1.21,1.52]$ & & \\
\hline Rwanda 2005 & 135 & 3386 & 67 & 2245 & $7.8 \%$ & $1.35[1.00,1.82]$ & & \\
\hline Malawi 2004 & 226 & 1545 & 129 & 1141 & $9.2 \%$ & $1.34[1.07,1.69]$ & & \\
\hline Zambia 2007 & 527 & 2978 & 356 & 2523 & $11.0 \%$ & $1.31[1.13,1.52]$ & & \\
\hline Sierra Leone 2008 & 45 & 2673 & 14 & 759 & $3.6 \%$ & $0.91[0.50,1.67]$ & T & \\
\hline Dominican Republic 2007 & 87 & 12370 & 97 & 12188 & $7.9 \%$ & $0.88[0.66,1.18]$ & 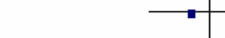 & \\
\hline Liberia 2007 & 72 & 4209 & 43 & 2157 & $6.3 \%$ & $0.86[0.58,1.25]$ & . & \\
\hline Total $(95 \% \mathrm{Cl})$ & & 50251 & & 40920 & $100.0 \%$ & $1.39[1.21,1.59]$ & & \\
\hline Total events & 2554 & & 1780 & & & & & \\
\hline \multicolumn{7}{|c|}{$\begin{array}{l}\text { Heterogeneity: } \mathrm{Tau}^{2}=0.04 ; \mathrm{Chi}^{2}=40.28, \mathrm{df}=14(\mathrm{P}=0.0002) ; \mathrm{I}^{2}=65 \% \\
\text { Test for overall effect } \mathrm{Z}=4.77(\mathrm{P}<0.00001)\end{array}$} & $\begin{array}{lll}0.5 & 0.7 & 1\end{array}$ & 1.52 \\
\hline Test for overall effect: $Z=$ & $77(\mathrm{P}<0.000$ & & & & & & lot currently employed & Currently employed \\
\hline
\end{tabular}

Figure 5. Prevalence of HIV infection among women age 15 - 49 years in relation to their status of employment (2003-2009).

sexual behaviour is known to predispose women for unplanned pregnancy and STI including HIV [23-25]. Besides the biological susceptibility, economic dependence and social vulnerability [8], the risky sexual practice of women with better socioeconomic status might have contributed much for high prevalence of HIV infection among women in the studied countries as has been reported in several literature [1,26].

The question is, despite a worldwide campaign for about a quarter of a century to increase the public awareness on predisposing factors for HIV infection, why those women with better education still found practicing higher-risk sex? Several literature have also shown that good knowledge about consequences of risky sexual practice doesn't necessarily result in behaviour change and reduction in HIV/STI prevalence $[23,27,28]$. A systematic review on impact of interventions concluded that most interventions improved the knowledge, attitude and intention of study participants, but long-lasting behavioral changes were very insignificant [29]. In line with these reports, this meta-analysis has also shown the significant sexual risk taking behaviour of literate women, who are thought to have much better knowledge about the consequences of risky sex as compared with their less or not educated counterparts. Therefore, taking all these evidences into account, one may conclude that lack of knowledge about risks of STI/HIV hasn't been the major determinant for sexual risk taking behaviour of better educated women in the selected countries.

On the other hand, poverty has been considered as driving factor for acquiring and propagating STI/HIV infection by several investigators [27,28,30-32] although others reported totally contradictory results $[4,10]$. This meta-analysis has also shown that higher-risk sex was significantly associated with women having middle to highest wealth index. Additionally, in the majority of selected countries, HIV infection was found highly prevalent among employed women who are expected to have better economic capacity than their unemployed counterparts.

If knowledge or poverty has not been a major determinant for risk taking sexual behaviour, so what is it? Previous reviewer had also raised similar question for high prevalence of HIV infection among women and men with higher socioeconomic status- -if poverty is not the problem, then what is?" [32]. What makes this issue so puzzling and contradictory to the expectation is that because it is so logical to accept and easy to explain the contribution of poverty and lack of education for engagement in risky sexual practice; since women struck by poverty may join the sex trade in some countries, and engage in unprotected sex for their survival, and the lack of education or information about the deadly consequence of risky sex may make them vulnerable for STI including HIV. However, the literature reviews and this meta-analysis showed findings contradictory to the expectations.

Taking the high risk taking sexual behaviour of better educated and wealthier women, we draw some hypotheses which are schematically presented in Figure 6. To begin with, although this is not limited to educated and wealthier women, awareness about the availability of antiretroviral therapy (ART) in the last decade probably contributed for a false sense of security to exercise risky sexual practice. Since the Congress of the United States approved the President's Emergency Plan for AIDS 


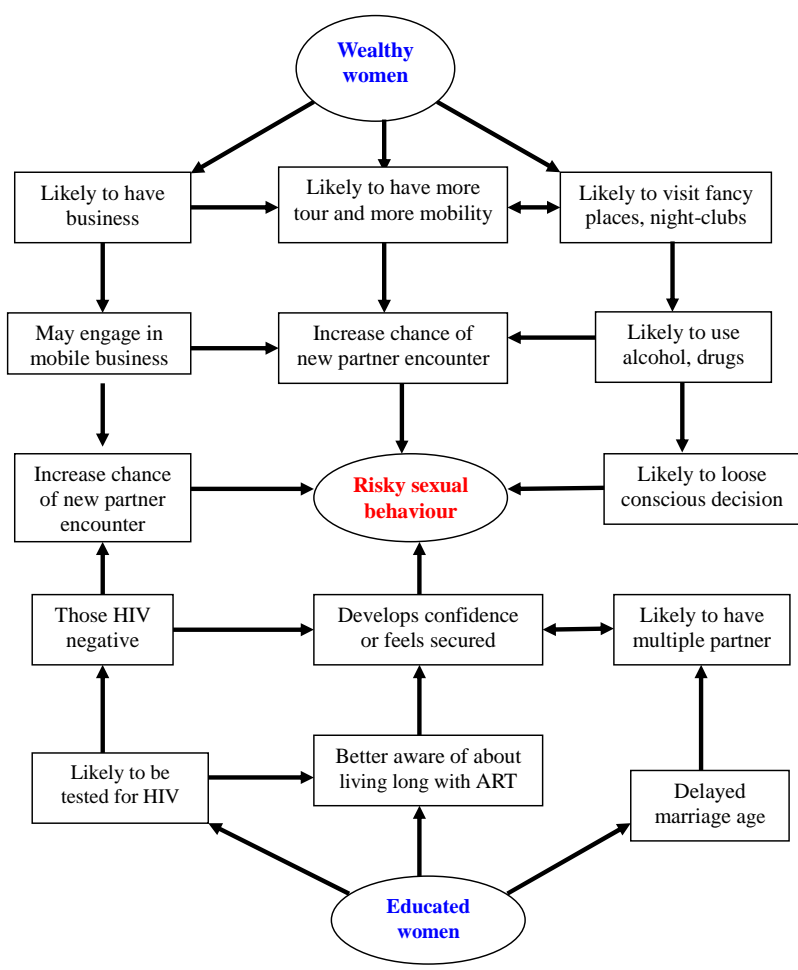

Figure 6. Schematic presentation of the discussion section (why literate and wealthy women engaged in higher-risk sex?).

Relief (PEPFAR) in 2003, ART has been provided free of charge for HIV infected patients in the third world countries. As a result, the positive change in nutritional and functional status of ART users has been likely very visible for the majority, which could have contributed for a false sense of security to practice risky sex. One of the recent reviews concluded that the expansion of ART would increase risky sexual behaviour among HIVnegative individuals because of awareness about increased life expectancy among patients on ART [33]. It should be noted that with the introduction of ART, the risky sexual behaviour of HIV-positive patients on ART has been reported as unchanged or insignificantly decreased [34-36] and increased [37].

Secondly, the negative HIV test result is probably another contributing factor for a false sense of reassurance to exercise risky sexual practice. The HIV testing campaign and as well the HIV test uptake has increased significantly in the last decade [38], which is also likely to increase the number of HIV negative women. A number of studies well described the increased or unchanged sexual risk taking behaviour of women tested HIV negative; some even attributed that a negative HIV test may be interpreted as endorsement of risky behaviour [38-40].

Thirdly, having the economic potential to buy something that brings pleasure is probably behind all the sexual risk taking behaviour of women. It is known that sexual pleasure is one means of enjoyment which is very likely to be thought and practiced when basic needs are fulfilled unless the sexual practice is meant for earning money for survival. Why women with good economic status were found engaged in higher-risk sex? Some well to do women may have a gambling sexual behaviour when there is sexual disharmony or failure to conceive with their regular partner. Some women who fulfill their material and financial need may be as well interested in adventure by having sex with as many men as possible. Still more important one; it is those women with good economic status who can buy and use substances including alcohol and drugs, which are known to distort the sexual-risk avoidance decision making. Studies from different parts of the world in different circumstances showed a strong association between substance use and risky sexual behavior [41,42].

Fourthly, wealthy and educated women have increased chance of travel or migration for making business or pleasure tour (local and distant), which is likely to increase their chance of encountering new sexual partner and adapting new behaviors. It was identified that migration increases HIV spread primarily by increasing highrisk sexual behaviour [43]. In a study involving female university students assigned from different parts of the country, their risky sexual behaviours (manifested by low condoms use and having multiple sexual partners) were strongly associated with good income, attending nightclubs and watching sex films [44].

Fifthly, educated women are likely to delay their age of marriage that may likely to expose them for having multiple and non-regular sexual partner. This is because particularly those women who joined higher education are very likely to delay their age of marriage primarily because of lengthy nature of the education, and secondly, because of delay in their husband selection, which is usually decided after each other being well studied. Some reports have also shown that better education attainment for women is more likely to delay their marriage for different reasons $[45,46]$. This is despite a high age at marriage in a population known to lead to a long period of premarital sex during which time partner changes are relatively common and thus likely to increase risky sexual practice and the spread of HIV [45,47-49].

In our opinion, the unhealthy sexual behaviour and high HIV prevalence observed among better educated and wealthier women seems directly or indirectly more related to economic capacity and exposures than to educational attainment. For those women who have the aspiration, economic capacity matters to get relaxed, appears seductive, become mobile for business or for recreation and interested in sexual adventure. On the other hand, better educated women are expected to delay their marriage, develop false sense of security/reassurance 
because of high chance of HIV testing and access for information.

In conclusion, it was reported that new HIV infections are declining globally which is mainly attributed to behavioral changes [1]. However, as this meta-analysis has shown, the high prevalence of higher-risk sexual behaviour and HIV infection among wealthier and better educated women regardless of the geographic location, the previous report [1] doesn't seem holds true for women in relatively well to do segment of the population in the studied countries. As a result, further study is required to establish how and why being good in socioeconomic status associated with risky sexual behaviour.

\section{Acknowledgements}

We would like to acknowledge MEASURE DHS for providing the DHS data in the form of PDF. For this work, we haven't got any financial or technical support. But the encouragement we got from Eden Asefa and Dr. Mebrat Deribe was energizing.

\section{REFERENCES}

[1] Joint United Nations Programme on HIV/AIDS (UNAIDS), "2010 Report on the Global AIDS Epidemic”. www.unaids.org

[2] J. Hargreaves and T. Boler, "Girl Power: The Impact of Girls' Education on HIV and Sexual Behaviour,” Action Aid International, 2006. www.actionaid.org.uk/doc_lib/girl

[3] N. Madise, E. Zulu and J. Ciera, "Is Poverty a Driver for Risky Sexual Behaviour? Evidences from National Surveys of Adolescents in Four African Countries," African Journal of Reproductive Health, Vol. 11, No. 3, 2007, pp. 83-98. doi:10.2307/25549733

[4] V. Mishra, S. B. V. Assche, R. Greener, M. Vaessen, R. Hong, P. D. Ghys, et al., "HIV Infection Does not Disproportionately Affect the Poorer in Sub-Saharan Africa," AIDS, Vol. 21, No. 7, 2007, pp. 17-28. doi:10.1097/01.aids.0000300532.51860.2a

[5] J. R. Hargreaves and J. R. Glynn, "Educational Attainment and HIV-1 Infection in Developing Countries: A Systematic Review,” Tropical Medicine and International Health, Vol. 7, No. 6, 2002, pp. 489-498. doi:10.1046/j.1365-3156.2002.00889.x

[6] Centers for Disease Control and Prevention, "HIV/AIDS Surveillance Report, 2007”. http://www.cdc.gov/hiv/topics/surveillance/

[7] D. R. Holtgrave and R. A. Crosby, "Social Capital, Poverty, and Income Inequality as Predictors of Gonorrhoea, Syphilis, Chlamydia and AIDS Case Rates in the United States," Sexually Transmitted Infection, Vol. 79, No. 1, 2003, pp. 62-64. doi:10.1136/sti.79.1.62

[8] J. A. Higgins, S. Hoffman and S. L. Dworkin, "ReThinking Gender, Heterosexual Men, and Women's Vulnerability to HIV/AIDS: Time to Shift the Paradigm,”
American Journal of Public Health, Vol. 100, No. 3, 2010, pp. 435-445.

[9] S. Leclerc-Madlala, “Age-Disparate and Intergenerational Sex in Southern Africa: The Dynamic of Hyper Vulnerability,” AIDS, Vol. 22, No. 4, 2008, pp. 17-24. doi:10.1097/01.aids.0000341774.86500.53

[10] L. Fenton, "Preventing HIV/AIDS through Poverty Reduction: The Only Sustainable Solution,” The Lancet, Vol. 364, No. 9440, 2004, pp. 1186-1187. doi:10.1016/S0140-6736(04)17109-2

[11] B. Lopman, J. Lewis, C. Nyamukapa, P. Mushati, S. Chandiwana and S. Gregson, "HIV Incidence and Poverty in Manicaland, Zimbabwe: Is HIV Becoming a Disease of the Poor?" AIDS, Vol. 21, No. 7, 2007, pp. 57-66. doi:10.1097/01.aids.0000300536.82354.52

[12] D. E. Bloom and J. Sevilla, "Health, Wealth, AIDS, and Poverty," Report of the Asia-Pacific Ministerial Meeting, The Australian Government Overseas Aid Programme, Melbourne, 9-10 October 2001.

www.ausaid.gov.au/publications/pdf/health_wealth_pove rty

[13] United Nations Development Programme, "HIV/AIDS Implications for Poverty Reduction,” 2001. www.worldbank.org/INTHIVAIDS

[14] L. Robertson, P. Mushati, J. Eaton, et al., "P1-S6.04 Education and Lifetime Risk of HIV Infection in Manicaland, Zimbabwe," Sexually Transmitted Infection, Vol. 87, No. 1, 2011, p. 197. doi:10.1136/sextrans-2011-050108.228

[15] A. K. Asare and S. K. Annim, "Wealth Status and Risky Sexual Behaviour in Ghana and Kenya," Applied Health Economics and Health Policy, Vol. 6, No. 1, 2008, pp. 2739. doi:10.2165/00148365-200806010-00003

[16] C. T. Kirunga and J. P. M. Ntozi, "Socio-Economic Determinants of HIV Serostatus: A Study of Rakai District, Uganda,” Health Transition Review, Vol. 7, No. 1, 1997, pp. 175-188.

[17] Demographic and Health Survey, Publication Search by Country. http://www.measuredhs.com/pubs/search_results.cfm

[18] Demographic Health Survey Questionnaires and Modules, "HIV/AIDS-Related Knowledge, Attitudes, and Behaviour Module".

http://www.measuredhs.com/pubs/DHSQM/DHS

[19] The Cochrane Collaboration, "Review Manager 5 (RevMan5, Cochrane Collaboration, Oxford, England)”. http://ims.cochrane.org/revman

[20] A. D. Burgoyne and P. D. Drummond, "Knowledge of HIV and AIDS in Women in Sub-Saharan Africa," African Journal of Reproductive Health, Vol. 12, No. 2, 2008, pp. 14-31.

[21] International Center for Research on Women, "Can Economic Empowerment Reduce Vulnerability of Girls and Young Women to HIV? Emerging Insights,” 2010. http://www.populationreports.org/m18/

[22] S. D. Weiser, K. Leiter, D. R. Bangsberg, L. M. Butler, F. P. Korte, Z. Hlanze, N. Phaladze, V. Iacopino and M. Heisler, "Food Insufficiency Is Associated with High- 
Risk Sexual Behavior among Women in Botswana and Swaziland,” PLoS Medicine, Vol. 4, No. 3, 2007, p. e260. http://www.plosmedicine.org/article/info

[23] C. Li, P. Jha, B. Stirling, S. K. Sgaier, T. Daid, R. Kaul and N. Nagelkerke, "Sexual Risk Factors for HIV Infection in Early and Advanced HIV Epidemics in Sub-Saharan Africa: Systematic Overview of 68 Epidemiological Studies," PLoS ONE, Vol. 2, No. 10, 2007, p. e1001.

http://www.plosone.org/article/info doi:10.1371/journal.pone.0001001

[24] K. Awusabo-Asari and S. K. Annim, "Wealth Status and Risky Sexual Behaviour in Ghana and Kenya," Applied Health Economics and Health Policy, Vol. 6, No. 1, 2008, pp. 27-39. doi:10.2165/00148365-200806010-00003

[25] K. Eugene, W. Charles, M. Robinson, N. Philip, L. Kouam, "Wealth and Sexual Behaviour among Men in Cameroon," BMC International Health Human Rights, Vol. 6, No. 11, 2006. www.biomedcentral.com/bmcinthealthhum

[26] Joint United Nations Programme on HIV/AIDS (UNAIDS), "2008 Report on the Global AIDS Epidemic". www.unaids.org

[27] D. Upreti, P. Regmi, P. Pant and P. Sinkhada, "Young People's Knowledge, Attitude, and Behaviour on STI/ HIV/AIDS in the Context of Nepal: A Systematic Review,” Kathmandu University Medical Journal, Vol. 7, No. 4, 2009, pp. 383-391.

[28] M. Aoife, A. David, M. Kaballa, B. Kathy, M. Clemens, A. Aura, L. Mary, I. N. Angela, A. Helen, K. Saidi, W. Deborah, C. John and J. Richard, “Long-Term Biological and Behavioural Impact of an Adolescent Sexual Health Intervention in Tanzania: Follow-Up Survey of the Community-Based MEMA kwa Vijana Trial,” PLoS Medicine, Vol. 7, No. 6, 2010, p. e1000287.

http://www.plosmedicine.org/article/info doi:10.1371/journal.pmed.1000287

[29] V. A. Paul-Ebhohimhen, A. Poobalan and E. R. Van Teijlingen, “A systematic Review of School-Based Sexual Health Interventions to Prevent STI/HIV in Sub-Saharan Africa,” BMC Public Health, Vol. 8, No. 4, 2008. http://www.biomedcentral.com/ doi:10.1186/1471-2458-8-4

[30] S. Gillespie, S. Kadiyala and R. Greener, "Is Poverty or Wealth Driving HIV Transmission?” AIDS, Vol. 21, No. 7, 2007, pp. 5-16. doi:10.1097/01.aids.0000300531.74730.72

[31] M. Vinoda, A. S. Bignami-Vanb, G. Robertc, V. Mrtina, H. Rathavutha, P, D. Ghys, B. J. Tiesd, V. A. Arie, K. Shanea, R. Sheaa, "HIV Infection Does Not Disproportionately Affect the Poorer in Sub-Saharan Africa," AIDS, Vol. 21, No. 7, 2007, pp. 17- 28. doi:10.1097/01.aids.0000300532.51860.2a

[32] A. M. Fox, "The Social Determinants of HIV Serostatus in Sub-Saharan Africa: An Inverse Relationship between Poverty and HIV?” Public Health Reproductive, Vol. 125, No. 4, 2010, pp. 16-24.

[33] A. Delavande and H. Kohler, "HIV-Related Expectations and Risky Sexual Behaviour in Malawi,” 2011. http://repository.upenn.edu/psc_working_papers/28
[34] S. Luchters, A. Sarna, S. Geibel, M. F. Chersich, P. Munyao, S. Kaai, et al., "Safer Sexual Behaviors after 12 Months of Antiretroviral Treatment in Mombasa, Kenya: A Prospective Cohort,” AIDS Patient Care STDS, Vol. 22, No. 7, 2008, pp. 587-594. doi:10.1089/apc.2007.0247

[35] T. P. Eisele, C. Mathews, M. Chopra, M. N. Lurie, L. Brown, S. Dewing and C. Kendall, "Changes in Risk Behavior among HIV-Positive Patients during Their First Year of Antiretroviral Therapy in Cape Town South Africa," AIDS and Behavior, Vol. 13, No. 6, 2009, pp. 1097-1105. doi:10.1007/s10461-008-9473-2

[36] R. Bunnell, J. P. Ekwaru, P. Solberg, N. Wamai, W. Bikaako-Kajura, W. Were, et al., "Changes in Sexual Behavior and Risk of HIV Transmission after Antiretroviral Therapy and Prevention Interventions in Rural Uganda," AIDS, Vol. 20, No. 1, 2006, pp. 85-92. doi:10.1097/01.aids.0000196566.40702.28

[37] S. Diabate, M. Alary and C. K. Koffi, "Short-Term Increase in Unsafe Sexual Behaviour after Initiation of HAART in Cote d'Ivoire,” AIDS, Vol. 22, No. 1, 2008, pp. 154-156.

[38] L. Sherr, B. Lopman, M. Kakowa, S. Dube, G. Chawira, C. Nyamukapa, N. Oberzaucher, I. Cremin and S. Gregson, "Voluntary Counselling and Testing: Uptake, Impact on Sexual Behaviour, and HIV Incidence in a Rural Zimbabwean Cohort,” AIDS, Vol. 21, No. 7, 2007, pp. 851860. doi:10.1097/QAD.0b013e32805e8711

[39] C. Wang, S. E. Hawes, A. Gaye, et al., "HIV Prevalence, Previous HIV Testing, and Condom Use with Clients and Regular Partners among Senegalese Commercial Sex Workers," Sexually Transmitted Infection, Vol. 83, No. 7, 2007, pp. 534-540.

[40] A. N. Turner, W. C. Miller, N. S. Padian, J. S. Kaufman, F. M. Behets, T. Chipato, F. A. Mmiro, R. A. Salata and C. S. Morrison, "Unprotected Sex following HIV Testing among Women in Uganda and Zimbabwe: Short- and Long-Term Comparisons with Pre-Test Behaviour," International Journal of Epidemiology, Vol. 38, No. 4, 2009, pp. 997-1007.

[41] M. Grossman and S. Markowitz, "I Did What Last Night?! Adolescent Risky Sexual Behaviors and Substance Use,” Eastern Economic Journal, Vol. 31, No. 3, 2005, pp. 383405.

[42] M. L. Cooper, “Alcohol Use and Risky Sexual Behavior among College Students and Youth: Evaluating the Evidence," Journal of studies on alcohol, Vol. 14, No. 1, 2002, pp. 101-117.

[43] M. Coffee and M. N. Lurie, "Garnett GP. Modeling the Impact of Migration on the HIV Epidemic in South Africa," AIDS, Vol. 21, No. 3, 2007, pp. 343-350. doi:10.1097/QAD.0b013e328011dac9

[44] Y. Berhan, D. Hailu and A. Alano, "Predictors of Risky Sexual Behaviour and Preventive Practices among University Students, Ethiopia,” African Journal of Aids Research, Vol. 10, No. 3, 2011, pp. 225-234. doi:10.2989/16085906.2011.626290

[45] Joint United Nations Programme on HIV/AIDS, “Acting Early to Prevent AIDS: The Case of Senegal,” 1999. data.unaids.org/publications/irc-pub04/una99-34_en.pdf 
[46] L. D. E. Ikamari, "The Effect of Education on the Timing of Marriage in Kenya,” Demographic Research, Vol. 12, No. 1, 2005, pp. 1-28. doi:10.4054/DemRes.2005.12.1

[47] T. Adair, "HIV Status and Age at First Marriage among Women in Cameroon," United States Agency for International Development, 2007.

pdf.usaid.gov/pdf_docs/PNADI793
[48] J. Bongaarts, "Late Marriage and the HIV Epidemic in Sub-Saharan Africa,” The Population Council, 2006. www.popcouncil.org/pdfs/wp/216.pdf

[49] J. G. Fortson, "The Gradient in Sub-Saharan Africa: SocioEconomic Status and HIV/AIDS,” Demography, Vol. 45, No. 2, 2008, pp. 303-322. doi:10.1353/dem.0.0006 